\title{
Effect of eprosartan-based therapy on systolic blood pressure and total cardiovascular risk in a large international population: preliminary report of the observational POWER study
}

\author{
This article was published in the following Dove Press journal: \\ Vascular Health and Risk Management \\ 24 September 2012 \\ Number of times this article has been viewed
}

\author{
Assen Goudev' \\ Jean-Pascal Berrou ${ }^{2}$ \\ Atul Pathak ${ }^{3}$ \\ On behalf of the POWER \\ Investigators \\ 'Department of Cardiology, Queen \\ Giovanna University Hospital, Sofia, \\ Bulgaria; ${ }^{2}$ Strategic Medical Affairs, \\ CardioMetabolic Established Products, \\ Abbott Products Operations AG, \\ Allschwil, Switzerland; ${ }^{3}$ Faculte' de \\ Médecine et CHU Toulouse, Unité de \\ Pharmacologie Cardiovasculaire et \\ Autonome, Service de Pharmacologie \\ et Cardiologie, INSERM U I048, \\ Université Paul Sabatier, Toulouse, \\ France
}

Background: Estimation of total cardiovascular risk is useful for developing preventive strategies for individual patients. The POWER (Physicians' Observational Work on Patient Education According to their Vascular Risk) survey, a 6-month, open-label, multinational, post-marketing observational evaluation of eprosartan, an angiotensin II receptor blocker, was undertaken to assess the efficacy and safety of eprosartan-based therapy in the treatment of high arterial blood pressure in a large population recruited from 16 countries with varying degrees of baseline cardiovascular risk, and the effect of eprosartan-based therapy on total cardiovascular risk, as represented by the $\mathrm{SCORE}^{\circledR}$ (Systematic Coronary Risk Assessment) or Framingham risk equations.

Methods: Participating physicians recruited $>29,000$ hypertensive patients whom they considered to be candidates (according to specified criteria) for treatment with eprosartan $600 \mathrm{mg} /$ day, with other drugs added at the discretion of the physician.

Results: During treatment, systolic blood pressure decreased by $25.8 \pm 14.4 \mathrm{mmHg}$ to $134.6 \pm 11.4 \mathrm{mmHg}(P<0.001)$, mean diastolic blood pressure fell by $12.6 \pm 9.5 \mathrm{mmHg}$ to $81.1 \pm 7.6 \mathrm{mmHg}$, and pulse pressure fell by $13.2 \pm 13.5 \mathrm{mmHg}$ to $53.6 \pm 11.4 \mathrm{mmHg}$ (both $P<0.01)$. Calculated total cardiovascular risk declined in parallel with the reduction in blood pressure.

Conclusion: The POWER study has demonstrated, in a large and nonselected population, the feasibility and practicability of reducing total cardiovascular risk through systematic management of high blood pressure.

Keywords: hypertension, SCORE ${ }^{\circledR}$, Framingham, eprosartan, cardiovascular risk

\section{Introduction}

Elevated blood pressure is a powerful contributor to total cardiovascular risk. ${ }^{1}$ However, an estimation of total cardiovascular risk rather than a focus on individual risk factors is preferred as a guide to the optimal preventive strategies for individual patients. A range of risk estimation models has been devised for this purpose, including $\operatorname{SCORE}^{\circledR}$ (Systematic Coronary Risk Assessment). ${ }^{2}$

The POWER (Physicians' Observational Work on Patient Education According to their Vascular Risk) study, a large post-marketing survey of eprosartan, an angiotensin II receptor blocker, created opportunities to evaluate both the effectiveness and safety of eprosartan-based therapy in the treatment of high arterial blood pressure in a large population recruited in countries with varying degrees of baseline cardiovascular risk, 
and the effect of eprosartan-based therapy on total cardiovascular risk, as represented by the SCORE or Framingham risk equations. We report here the primary findings of POWER.

\section{Materials and methods}

POWER was an open-label, post-marketing observational study with a 6-month treatment phase. The survey was conducted in 16 countries (Bahrain, Belgium, Bulgaria, Canada, Croatia, Greece, South Korea, Kuwait, Poland, Qatar, Russia, Saudi Arabia, South Africa, Sweden, Thailand, and the United Arab Emirates). ${ }^{3}$

Participating physicians (general physicians or cardiologists) collected data for at least five sequentially recruited patients with newly diagnosed mild-to-moderate hypertension (mean sitting systolic blood pressure $>140 \mathrm{mmHg}$ ), which the physicians proposed to treat with eprosartan, or existing hypertension considered insufficiently well controlled by current therapy, or patients who were unable to tolerate other antihypertensive medications.

Initial medication comprised eprosartan $600 \mathrm{mg} /$ day. This could be supplemented with other antihypertensive drugs (preferably hydrochlorothiazide $12.5 \mathrm{mg} /$ day) if the blood pressure response after one month of eprosartan monotherapy was considered insufficient.

The primary efficacy objective of POWER was the absolute change in systolic blood pressure during the period of observation, calculated, if possible, as the mean of two readings obtained at each visit. Blood pressure was measured at baseline, at the intermediate visit scheduled for 1-3 months after the start of eprosartan-based therapy, and at the end of the 6-month period of observation. Blood pressure measurements were made using standard local methods regarded as reliable, accurate, and relevant.

The impact of eprosartan-based therapy on total cardiovascular risk was a specified secondary endpoint. ${ }^{3}$ The SCORE methodology was used for this purpose in 15 countries. Several methods were used to derive SCORE-based estimates of the absolute change in 10-year risk of fatal cardiovascular disease, as follows:

- The "recorded" SCORE risk was obtained directly by physicians using data recorded by them on the case-record forms and applied to the SCORE cardiovascular risk chart appropriate to the cardiovascular risk profile of the country in question (ie, low-risk, high-risk, or country-specific)

- The "calculated" SCORE risk was generated centrally using the appropriate SCORE risk chart and individual patient data collected by physicians and recorded on the case-record forms
- SCORE values were calculated using country-appropriate formulae and individual patient data collected by physicians, and recorded on the case-record forms.

For the Canadian contingent only, Framingham instruments were used to quantify cardiovascular risk because these were regarded as more appropriate to a North American population. The specific outcome considered was the absolute change in 10-year risk of "hard" coronary heart disease.

The POWER protocol was fully compatible with current rules and guidance for good clinical practice and the ethical conduct of research in humans, including the precepts of informed consent, and was subject to institutional review board and/or ethics committee review and approval as required by local regulations and practice. POWER also conformed to the provisions of the SCOPE initiative for the reporting of observational studies.

\section{Statistical analysis}

Given the size of the population, quantitative variables were compared with a one-sample $t$-test. Blood pressure and laboratory parameters were compared between visits using covariance analysis, with the baseline value as the adjusted variable. Other quantitative variables were compared by variance analysis. All tests were two-sided, with significance specified at the level of 5\% probability (ie, 0.05). Qualitative variables were compared using the Chi-squared test or by direct calculation of the degree of significance using Fisher's Exact test if nominal or by the Wilcoxon test or KruskalWallis test if ordinal.

\section{Results}

\section{Patients and demographics}

Between May 2005 and October 2009, a total of 29,754 patients were enrolled at 4158 centers. From this population, an intention-to-treat cohort of 26,192 patients was identified, comprising patients aged $\geq 18$ years who received at least one dose of study treatment and for whom systolic blood pressure and cardiovascular disease estimates were available at baseline and at least one subsequent visit (Figure 1). The median duration of treatment was 182 days. The mean age of the intention-to-treat population was $61.3 \pm 12.2$ years (range 18-99); 13,592 (52.3\%) were men, 6592 (25.3\%) were smokers at baseline, and mean body mass index was $28.2 \pm 4.8 \mathrm{~kg} / \mathrm{m}^{2}$. Demographic data are shown in Table 1 .

The mean ages of men $(59.5 \pm 12.1$ years $)$ and women $(63.3 \pm 12.0$ years $)$ in the intention-to-treat population differed significantly $(P<0.01)$. Age distribution also varied significantly by gender $(P<0.01)$, with men representing 


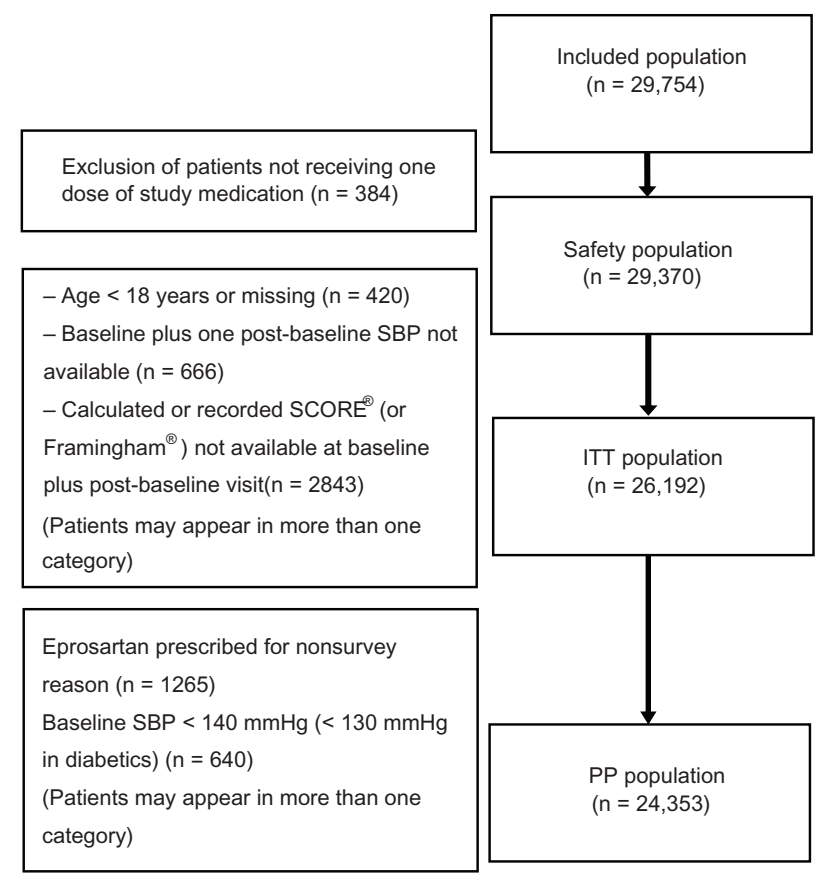

Figure I CONSORT diagram for the POWER patient population.

Abbreviations: ITT, intention-to-treat; PP, per protocol; SBP, systolic blood pressure.

proportionately more of the population aged 50-59 years (62.7\% versus $37.3 \%$ women) whereas women represented proportionately more of the population aged $>70$ years (58.7\% versus men $41.3 \%$ ). Of 10,437 patients for whom race information was recorded, 6523 (62.5\%) were classified as white and $3412(32.7 \%)$ as Asian. Numerically prominent cardiovascular-relevant pathologies included diabetes, left ventricular hypertrophy, and arteriosclerosis (5801 [22.6\%], 4987 [19.4\%], and 4961 [19.3\%], respectively).

\section{Blood pressure data}

Approximately one-third of patients were assigned each to monotherapy (eprosartan only), to dual therapy, or to multidrug therapy during the survey. Detailed distributions of drug therapy during the survey are presented in Figure 2. Combination therapy was more often encountered in men, in older or diabetic patients, and in those with a significant cardiovascular history. The proportion of patients with isolated systolic hypertension increased with age, ie, $26.5 \%(\mathrm{n}=1932)$ at age $60-69$ years and $34.0 \%(\mathrm{n}=2385)$ at age $>70$ years, compared with $16.0 \%(\mathrm{n}=691)$ and $19.6 \%(\mathrm{n}=1457)$, respectively, at age $<50$ years and $50-59$ years.

Baseline mean arterial blood pressure in the intentionto-treat population was $160.4 \pm 14.3 / 93.6 \pm 9.7 \mathrm{mmHg}$ and mean pulse pressure was $66.9 \pm 14.3 \mathrm{mmHg}$. Systo-diastolic hypertension was documented in 18,741 patients $(72.5 \%)$
Table I Demographic characteristics of the POWER intentionto-treat population $(n=25,078)$

\begin{tabular}{ll}
\hline Demographic characteristics & $\begin{array}{l}\text { ITT population } \\
(\mathbf{n}=\mathbf{2 6 , 1 9 2 )} \\
(\mathbf{n}, \%)\end{array}$ \\
\hline Gender (n, \%) & $\mathrm{n}=25,986$ \\
Men & $13,592(52.3 \%)$ \\
Women & $12,394(47.7 \%)$ \\
Age (years) & $\mathrm{n}=26,192$ \\
Mean \pm SD & $61.3 \pm 12.2$ \\
$<50$ & $4347(16.6 \%)$ \\
$50-59$ & $7448(28.4 \%)$ \\
$60-69$ & $7345(28.0 \%)$ \\
$\geq 70$ & $7052(26.9 \%)$ \\
Height (cm) & $\mathrm{n}=25,035$ \\
Mean \pm SD & $168.5 \pm 9.2$ \\
Weight (kg) & $\mathrm{n}=24,912$ \\
Mean \pm SD & $80.2 \pm 15.4$ \\
BMI (kg/m $\left.{ }^{2}\right)$ & $\mathrm{n}=24,190$ \\
Mean \pm SD & $28.2 \pm 4.8$ \\
Waist circumference (cm) & $\mathrm{n}=15,819$ \\
Mean \pm SD & $96.5 \pm 14.9$ \\
Race & $\mathrm{n}=10,437$ \\
White & $6523(62.5 \%)$ \\
Asian & $3412(32.7 \%)$ \\
Black of African heritage or African American & $383(3.7 \%)$ \\
American Indian or Alaska American & $74(0.7 \%)$ \\
Colored (only for South Africa) & $25(0.2 \%)$ \\
Native Hawaiian or other Pacific Islander & $12(0.1 \%)$ \\
Other, specify (Canada only) & $8(0.1 \%)$ \\
Smoking status & $\mathrm{n}=26,011$ \\
Yes & $6592(25.3 \%)$ \\
\hline Not Sample siss & \\
\hline &
\end{tabular}

Note: Sample sizes of some variables differ from intention-to-treat total due to lack of recorded data.

Abbreviations: BMI, body mass index; ITT, intention-to-treat; SD, standard deviation.

and isolated systolic hypertension in $6429(24.9 \%)$. Systolic blood pressure increased with age (mean systolic blood pressure $161.1 \pm 14.7 \mathrm{mmHg}$ at age $>70$ years versus $158.9 \pm 14.0 \mathrm{mmHg}$ at age $\leq 50$ years) whereas diastolic blood pressure decreased with age $(91 \pm 10.1 \mathrm{mmHg}$ at age $>70$ years versus $96.1 \pm 9.1 \mathrm{mmHg}$ at age $\leq 50$ years). As a consequence, pulse pressure increased with age.

Mean systolic blood pressure in the intention-to-treat population decreased by $25.8 \pm 14.4 \mathrm{mmHg}$ during the survey ( $P<0.001$ versus baseline). Mean diastolic blood pressure decreased by $12.6 \pm 9.5 \mathrm{mmHg}$ and mean pulse pressure decreased by $13.2 \pm 13.5 \mathrm{mmHg}$ (both $P<0.01$ versus baseline). Antihypertensive efficacy was evident in all subsets of the population, including patients with diabetes or other forms of high baseline cardiovascular risk.

Approximately $62 \%$ of patients reached the predefined target of systolic blood pressure $<140 \mathrm{mmHg}$ plus diastolic blood pressure $<90 \mathrm{mmHg}$ at the end 
A

- Eprosartan ony $\quad=2$ drugs $\quad 3$ drugs or more $\quad$ Imprecise data

B Eprosartan ony $\quad 2$ drugs $\square 3$ drugs or more

Imprecise data
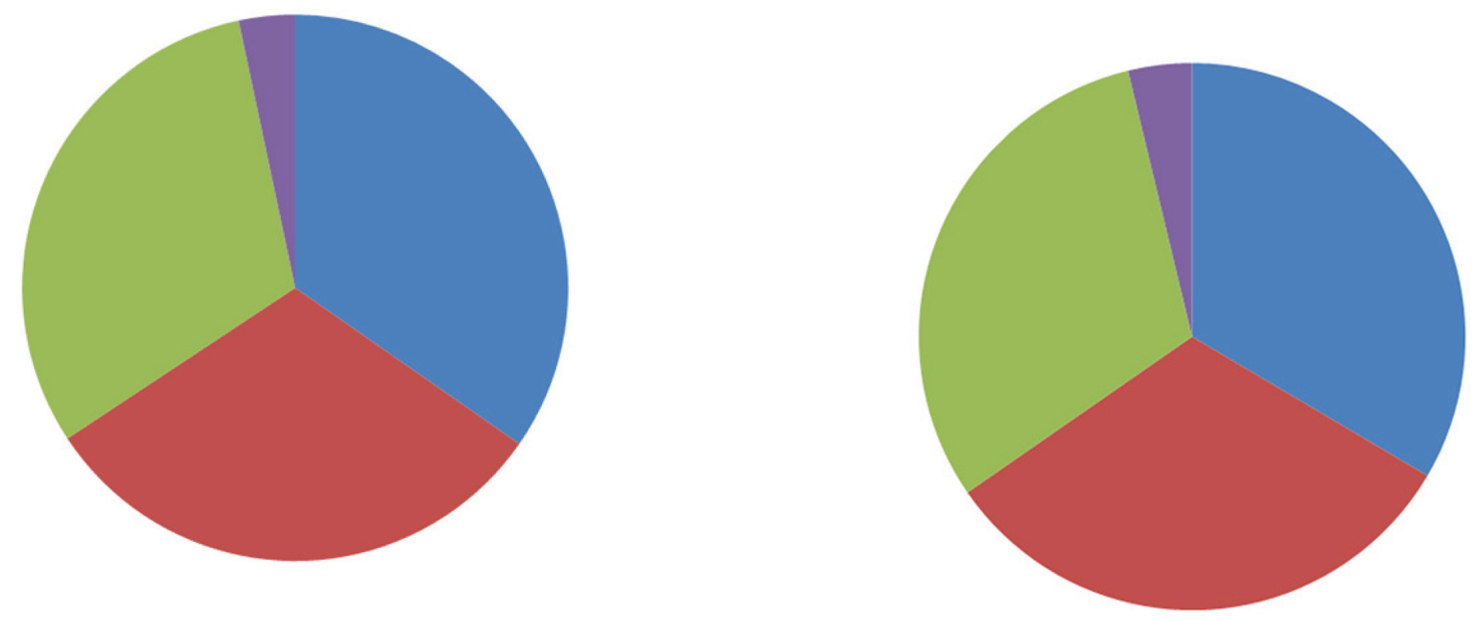

C $\square$ Eprosartan ony $\square 2$ drugs $\square 3$ drugs or more $\square$ Imprecise data

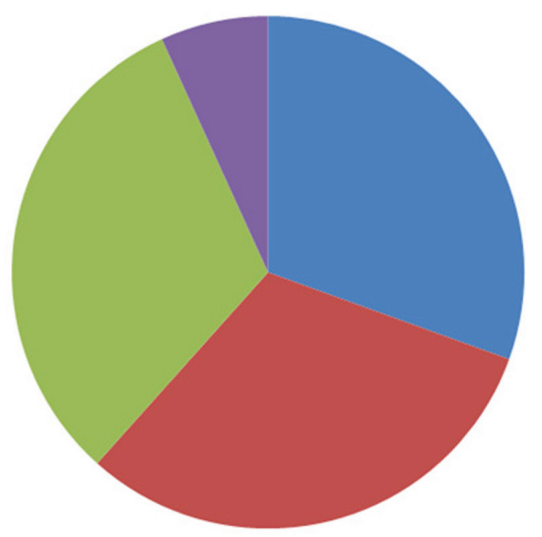

Figure 2 Patterns of antihypertensive prescribing at (A) baseline, and at (B) 3 and (C) 6 months in the POWER survey. Drugs most frequently recorded as supplements to eprosartan at each time point are listed in the notes.

Notes: (A) beta-blockers, 8286 (31.6\%); calcium antagonists, 6323 (24.1\%); diuretics other than hydrochlorothiazide, 4996 (19.1\%); angiotensin-converting enzyme inhibitors, 2755 (10.5\%). (B) beta-blockers, 7458 (28.9\%); calcium antagonists, 5798 (22.5\%); fixed-dose combination of eprosartan-hydrochlorothiazide, 5005 (19.4\%); diuretics other than hydrochlorothiazide, 4055 (I5.7\%). (C) beta-blockers, 7288 (28.6\%); fixed-dose combination of eprosartan-hydrochlorothiazide, 6028 (23.7\%); calcium antagonists, 5787 (22.7\%); diuretics other than hydrochlorothiazide, 3778 (14.8\%).

of the observation period; $>90 \%$ of patients met the definition of a responder to eprosartan-based therapy (systolic blood pressure $<140 \mathrm{mmHg}$ and/or a change in systolic blood pressure $\geq 15 \mathrm{mmHg}$ or diastolic blood pressure $<90 \mathrm{mmHg}$ and/or change in diastolic blood pressure $\geq 10 \mathrm{mmHg}$ ).

\section{Total cardiovascular risk}

Some $40 \%$ of patients $(n=10,597)$ had a family history of cardiovascular disease. In all, 4518 patients had documented coronary artery disease and 1416 had a history of congestive heart failure. There were 1305 patients with a history of ischemic stroke and 1029 patients had renal failure. These patients, and others, were excluded from the SCORE calculations because of their secondary prevention status.

Cardiovascular risk was calculated using the SCORE method in all countries except Canada; the mean cardiovascular risk estimate in patients of the 15 countries that used the SCORE method declined by about $40 \%$ during the period of observation. In Canada only, cardiovascular risk was calculated using Framingham instruments, and the mean cardiovascular risk score in the Canadian contingent decreased by approximately $27 \%$ during the period of observation. 


\section{Tolerability and adverse event data}

A total of 730 adverse events were recorded in 530 subjects $(1.8 \%$ of the safety population $[n=29,370])$. Of these, 493 incidents were recorded as suspected adverse drug reactions, including 45 reactions that were classified as "severe" and 14 that were classified as "serious" (Table 2). Five of the seven deaths recorded were judged unrelated or unlikely to be related to medication use. The other two deaths were classified as suspect because the investigators did not file an assessment of likely causal relation to medication use.

\section{Discussion}

This investigation of 6 months' duration has demonstrated in a large and nonselected population the feasibility and practicability of eprosartan-based therapy (either as eprosartan monotherapy or in combination regimens) to control arterial blood pressure, especially its systolic component, and, as a result, to reduce total cardiovascular risk. This general effect is in line with expectations of the impact of sustained reduction in systolic blood pressure on overall cardiovascular risk, and is consistent with the findings of an earlier meta-analysis of the effect of angiotensin II receptor blocker treatment on risk of major cardiovascular events. ${ }^{4}$

The mean systolic blood pressure reduction recorded in POWER was about $26 \mathrm{mmHg}$. Allowance needs to be made for the lack of placebo correction applied in the POWER survey, but this scale of effect, although large, is not implausible, especially when it is considered that a majority of patients were prescribed eprosartan-based therapy, not eprosartan monotherapy. ${ }^{5,6}$ Use of combination therapy in order to achieve satisfactory blood pressure control, with a thiazide diuretic being the dominant choice, has been a feature

Table 2 Summary of suspected adverse drug reactions in the POWER safety population $(n=29,370)$

\begin{tabular}{lll}
\hline & $\begin{array}{l}\text { Number of SADRs } \\
\text { (percentage of total } \\
\text { SADRs) }\end{array}$ & $\begin{array}{l}\text { Number of patients } \\
\text { with } \geq \text { I SADR } \\
\text { (percentage of } \\
\text { total patients) }\end{array}$ \\
\hline SADRs & $493(100 \%)$ & $374(1.3 \%)$ \\
SADRs leading to & $338(68.6 \%)$ & $256(0.9 \%)$ \\
study termination & & $1 \mathrm{I}(<0.1 \%)$ \\
Serious SADRs & $14(2.8 \%)$ & $36(0.1 \%)$ \\
Severe SADRs & $45(9.1 \%)$ & $7(<0.1 \%)$ \\
Deaths & 7 &
\end{tabular}

Abbreviation: SADR, suspected adverse drug reaction. of eprosartan clinical trials, and has been associated with double-digit reductions in mean systolic blood pressure. ${ }^{5,7}$ Of note, a reduction in mean systolic blood pressure was observed in POWER irrespective of patient gender, age, diabetic status, or cardiovascular history.

Cardiovascular risk status, as represented by mean SCORE values, improved substantially during the period of treatment and observation in POWER. In the absence of structured interventions against other major cardiovascular risk factors, it must be inferred that this effect was substantially, if not entirely, the result of the reduction in systolic blood pressure. Whether or not the reduction in mean SCORE value represents the maximum such effect that can be expected from the achieved degree of systolic blood pressure control remains to be established (see Guallar et $\mathrm{al}^{8}$ for a recent contribution in this area). It remains also to be established if the observed reduction in mean SCORE value represents a broad-based effect in the generality of the POWER population or if it is the result of an effect concentrated in a subset of patients with distinct demographic characteristics. Insights into these matters may be instructive to the development of primary care interventions for reduction of cardiovascular risk.

Eprosartan $600 \mathrm{mg}$ once daily was well tolerated in POWER when used alone or in combination. This experience is consistent with other reports of eprosartan. ${ }^{9,10}$ The overall profile of antihypertensive efficacy with favorable tolerability seen with once-daily eprosartan in POWER is consistent with, and supplements in circumstances of routine practice, data from controlled trials of angiotensin II receptor blockers, as recently reviewed. ${ }^{11,12}$ The large number of patients enrolled in the safety population confers power to detect rare adverse drug reactions, and it is noteworthy that no new adverse drug reactions were detected. However, continued and longer-term follow-up is needed to provide fuller assurances on that point.

The very large number of patients involved in this project creates opportunities to examine hypothesisgenerating effects in subgroups. Investigations of the effects of eprosartan-based therapy on total cardiovascular risk estimated by SCORE in 15 countries and by Framingham instruments in patients recruited in Canada are in progress, as are explorations of eprosartan-based therapy effects in the large subset of patients with diabetes. Data accrued in POWER may be useful for evaluating the role of risk assessment instruments as aids to resource allocation in cardiovascular prevention. ${ }^{13}$ 


\section{Disclosure}

The POWER study is supported financially by Abbott Products Operations AG, Switzerland. AG reports funding by Abbott, receipt of an honorarium from Abbott, and reimbursement for attending Abbott symposia. JP-B is an employee of Abbott, sponsor of the POWER observational study. AP reports funding by Abbott, receipt of an honorarium from Abbott, and reimbursement for attending Abbott symposia. Preparation of this report was assisted by Hughes associates, Oxford, UK.

\section{References}

1. Czernichow S, Zanchetti A, Turnbull F, et al. The effects of blood pressure reduction and of different blood pressure-lowering regimens on major cardiovascular events according to baseline blood pressure: meta-analysis of randomized trials. J Hypertens. 2011;29:4-16.

2. Conroy RM, Pyörälä K, Fitzgerald AP, et al. Estimation of ten-year risk of fatal cardiovascular disease in Europe: the SCORE project. Eur Heart J. 2003;24:987-1003.

3. De Backer G, Petrella JR, Goudev AR, et al. Design and methodology of POWER, an open-label observation of the effect of primary care interventions on total cardiovascular risk in patients with hypertension. Fundam Clin Pharmacol. November 4, 2011. [Epub ahead of print.]

4. Blood Pressure Lowering Treatment Trialists' Collaboration. Effects of different blood-pressure-lowering regimens on major cardiovascular events: results of prospectively-designed overviews of randomised trials. Lancet. 2003;362:1527-1535.
5. Ambrosioni E, Bombelli M, Cerasola G, et al. Ambulatory monitoring of systolic hypertension in the elderly: eprosartan/hydrochlorothiazide compared with losartan/hydrochlorothiazide (INSIST trial). Adv Ther. 2010;27:365-380.

6. Conter HS, McKay DW, Reiz RJ. Eprosartan mesylate effectively reduces systolic and diastolic blood pressure in a Canadian primary care setting. Can J Cardiol. 2004;20 Suppl C:6C-10C.

7. Schrader J, Lüders S, Kulschewski A, et al. Morbidity and mortality after stroke, eprosartan compared with nitrendipine for secondary prevention: principal results of a prospective randomized controlled study (MOSES). Stroke. 2005;36:1218-1226.

8. Guallar E, Banegas JR, Blasco-Colmenares E, et al. Excess risk attributable to traditional cardiovascular risk factors in clinical practice settings across Europe - The EURIKA Study. BMC Public Health. 2011;11:704.

9. Xu FY, Yang B, Shi D, Li H, Zou Z, Shi XY. Antihypertensive effects and safety of eprosartan: a meta-analysis of randomized controlled trials. Eur J Clin Pharmacol. 2012;68:195-205.

10. Böhm M, Sachse A. Safety and tolerability of eprosartan in combination with hydrochlorothiazide. Drug Saf. 2002;25:599-611.

11. Baumhäkel M, Böhm M. Cardiovascular outcomes with angiotensin II receptor blockers: clinical implications of recent trials. Vasc Health Risk Manag. 2011;7:391-397.

12. Flack JM, Nasser SA. Benefits of once-daily therapies in the treatment of hypertension. Vasc Health Risk Manag. 2011;7:777-787.

13. De Backer G. The SCORE model in the POWER study: an attempt to focus the limited resources for prevention on patients with greatest need. Curr Med Res Opin. 2007;23 Suppl 5:S19-S24.
Vascular Health and Risk Management

\section{Publish your work in this journal}

Vascular Health and Risk Management is an international, peerreviewed journal of therapeutics and risk management, focusing on concise rapid reporting of clinical studies on the processes involved in the maintenance of vascular health; the monitoring, prevention and treatment of vascular disease and its sequelae; and the involvement of

\section{Dovepress}

metabolic disorders, particularly diabetes. This journal is indexed on PubMed Central and MedLine. The manuscript management system is completely online and includes a very quick and fair peer-review system, which is all easy to use. Visit http://www.dovepress.com/ testimonials.php to read real quotes from published authors. 